\title{
Intelligent compaction technology for geomaterials. A demonstration project
}

\author{
António Gomes Correia ${ }^{a^{*}}$, Manuel Parente ${ }^{\mathrm{a}}$ \\ ${ }^{a} C-T A C-C e n t r e$ for Territory, Environment and Construction, School of Engineering of University of Minho, Guimarães, \\ Portugal
}

\begin{abstract}
Intelligent Compaction (IC), which is a part of Compaction Management, is a real time automatic adjustment and continuous compaction control technology of geomaterials or asphalt layers. The adjustment of the compaction parameters by the equipment is conducted simultaneously to the compaction process, as well as the continuous measurement of a dynamic compaction value, which is an indicator of the material's degree of compaction. This study seeks to assess the advantages and disadvantages of IC, as well as formulating a comparison with conventional compaction methods in terms of efficiency. This goal was achieved through in situ application of various technologies to two distinct types of material: a soil-rockfill mixture and a sandy soil. Data was obtained and analysed by the IC continuous information, as well as by the application of several different conventional compaction control tests and methods. Results show that the IC technology presents a superior performance, as well as various advantages when compared to conventional compactors.
\end{abstract}

Keywords: Compaction, intelligent compaction, compactors, soil, soil-rockfill mixtures, stiffness

\section{Résumé}

Le compactage intelligent (CI) qui fait partie de la gestion de compactage est une technologie d'ajustement automatique et de contrôle du compactage des sols ou des couches d'enrobé. L'ajustement des paramètres de compactage par l'équipement est effectué simultanément au procédé de compactage, ainsi que la mesure en continu d'une valeur de compaction dynamique, qui est un indicateur de la mesure du degré de compactage du matériau. Cette étude vise à évaluer les avantages et les inconvénients du CI, ainsi que sa performance avec les méthodes de compactage classiques en termes d'efficacité. Cet objectif a été atteint grâceà l'application de diverses technologies à deux types de matériaux: un mélange sol-enrochement et un sol sableux. Les données ont été obtenues et analysées par les informations en continu du CI, ainsi que par l'application de plusieurs essais et méthodes conventionnelles de contrôle du compactage. Les résultats montrent que la technologie CI présente un rendement supérieur, ainsi que divers avantages par rapport aux compacteurs classiques.

Mots-clé: Compactage, compactage intelligent, compacteurs, sols, mélanges sol-enrochement, raideur

* Tel.: +351- 253510214; fax: +351-253510217

E-mail address: agc@ civil.uminho.pt
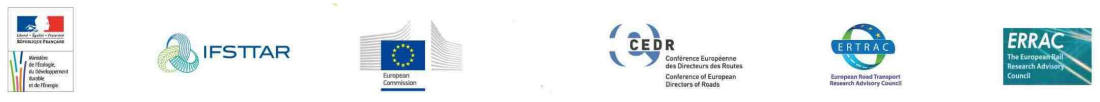


\section{Introduction}

The concept of Compaction Management (also referred to as Intelligent Compaction, IC) initially appeared in Europe around 1980 (Forssblad, 1980; Thurner \& Sandström, 1980), although it has recently been subject of significant study and development in the U.S. by the FHWA (Federal Highway Administration) (Camargo et al., 2006; Petersen, 2005; White et al., 2007).

This technology combines continuous measurement of the material degree of compaction (Gomes Correia \& Quibel, 2000) with feedback from the vibratory drum, which enhances the equipment with the capability to adjust the applied compaction energy depending on the measured material conditions. These features are based on a roller integrated system (Adam \& Brandl, 2003), including components such as accelerometers that measure drum vibration, onboard electronics that record and process sensor output and material stiffness, associated with linkage elements to the machine controls that allow for compaction effort adjustment according to measured stiffness, GPS system to record machine location and local storage or wireless communication system for data transfer (Adam, 2007; Rinehart \& Mooney, 2008). As a consequence, the equipment gains the ability to regulate its vibratory intensity automatically and in real time, in function of the current measured degree of compaction of the material, thus being able to increase compaction effort in areas that have not yet reached the specified target value, while preventing overcompaction (Brandl, 2001) of areas that have achieved or exceeded this value (Anderegg \& Kaufmann, 2004). This leads not only to an increase in the foundation quality, but also to the subsequent improvement of the pavement long-term performance, as a direct consequence of superior compaction uniformity and quality on the foundation. Furthermore, both an increase in productivity and a reduction of costs during the compaction process are also associated with this technology (Hildebrandt, 2005).

With the aim of assessing the advantages and disadvantages of this IC technology compared with the conventional one, this paper begins with the description of the demonstration project carried out for that purpose, including two types of geomaterials, available compaction equipments and construction planning. Compaction efficiency of the compactors on both soil-rockfill mixture and soil materials with different thicknesses used in the experimental sections is analysed through different monitoring devices and the conclusions are presented.

\section{Demonstration project}

The current demonstration project was prepared at a road construction site in Alijó, Portugal. The test section area was 9x160 metres and consisted of three lanes, 3 meters each, with different layer thicknesses, divided in sections with $40 \mathrm{~m}$ of length, and two type of materials (soil-rockfill mixture and a sandy soil), as depicted in Figures 3 and 4. In the soil-rockfill section, these thicknesses of 0,55, 0,75 and 1,00m were tested covering the tolerable range suggested by the Guide to Earthwork Construction (GTR) (SETRA \& LCPC, 1992). The soil section was prepared with $0,45 \mathrm{~m}$ thickness, also following the recommendation of the same guide. The foundation material is a residual soil of granite where singularity zones of low and high stiffness were constructed. These singularities aim to evaluate how IC technology is able to detect them and change vibration parameters to achieve an efficient compaction for each of the layer thicknesses.

\subsection{Materials}

As previously referred, two types of material were used in the IC demonstration project: soil and a soil-rockfill mix. The soil-rockfill mix excavated from the construction site was used in the first phase of the project, which, according to the GTR regulation was classified as a $C_{1} B_{1}$ material, since $60-80 \%$ of it is comprised in the $0-50$ $\mathrm{mm}$ fraction as a B type material. The referred $0-50 \mathrm{~mm}$ fraction consists of less than $12 \%$ of particles inferior to $80 \mu \mathrm{m}$, as well as more than $70 \%$ of particles inferior to $2 \mathrm{~mm}$. Simultaneously, the methylene blue value for this material is between 0,1 and 0,2 , concluding that the $0-50 \mathrm{~mm}$ fraction of the soil-rockfill mix material is, in fact, a $B_{1}$ (Fig. 1a).

As far as the soil material is concerned, it falls under a $\mathrm{B}_{1}$ material, designated as a fines-poor sand soil according to the GTR standards, and its maximum dry density and optimum moisture content are $1,947 \mathrm{~g} / \mathrm{cm}^{3}$ and 9,6\%, respectively, as obtained from the Modified Proctor test results (Fig. 1b). 

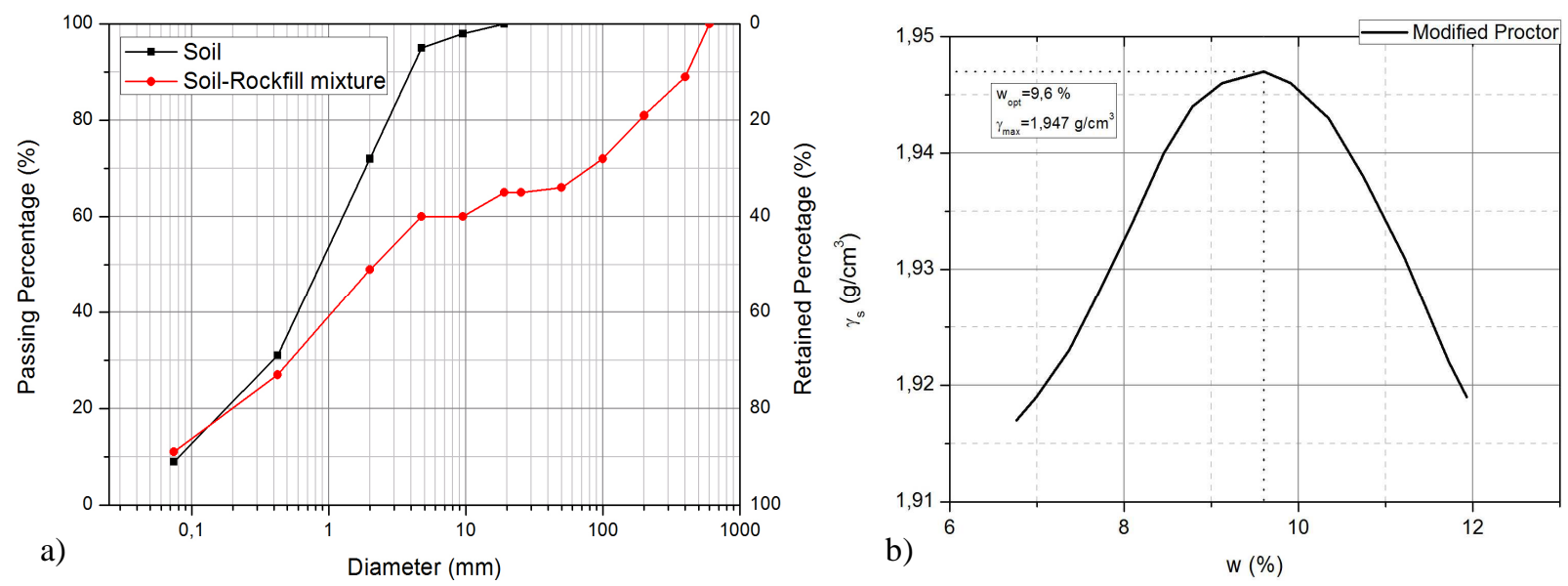

Fig. 1. (a) grading curves of soil and soil-rickfill mixture; (b) modified Proctor test results

\subsection{Equipment}

The available compaction equipment for the demonstration project was a BOMAG BW 213 DH-4 BVC (equipped with IC technology), with a load per unit of length (W/L) of 44,1 kg/cm and a maximum amplitude $\left(\mathrm{A}_{0}\right)$ of $2,5 \mathrm{~mm}$, and a regular Caterpillar model CS $683 \mathrm{E}$, with a W/L of $62,3 \mathrm{~kg} / \mathrm{cm}$ and $\mathrm{A}_{0}$ of $1,8 \mathrm{~mm}$. Considering those characteristics, these rollers were classified as compactor classes V4 and V5, respectively, according to the GTR, although this guide does not incorporate the classification of rollers equipped with IC technology.

The available equipment fleet also included:

- Articulated A40 Dumpers for transportation;

- Bulldozer D8 for material spreading;

- Cat $14 \mathrm{H}$ for layer surface levelling; and

- Water truck to moisten the layer.

Regarding compaction control, the available equipment featured Falling Weight Deflectometer (FWD) and static plate loading test (SPLT) equipment. Furthermore, topographical reference plates were used to control settlement throughout the compaction process in the case of soil-rockfill layers, while nuclear moisture density gauge was used to verify the degree of compaction and water contents in the case of the soil layer.

\subsection{Foundation evaluation and layer construction}

The demonstration project began with the characterization of the foundation, consisting of in-situ soil-rockfill material. This material falls under the same GTR class used in the construction of the soil-rockfill layers. The evaluation of the foundation included measurement passes with the IC compactor, as well as SPLT on 9 locations and FWD measurements throughout the length of the test section's area. Some of these measurements (Fig. 2a) are adapted from Gomes Correia \& Magnan (2012) and are discussed further on. The SPLT and IC results were also used in this phase to attempt to establish a correlation between both measurement methods, having achieved a good correlation factor $\left(\mathrm{R}^{2}\right.$ around 0,84$)$ within the obtained value range (Fig. 2b). 

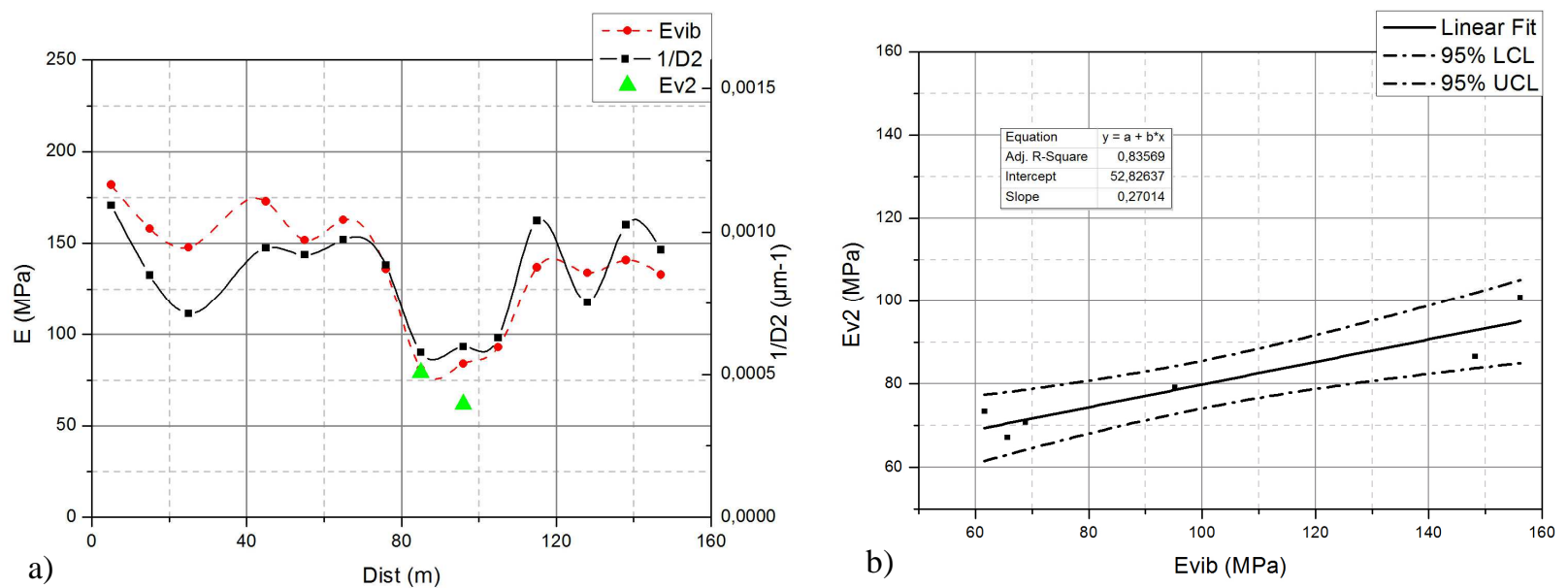

Fig. 2. (a) IC measurement passes, FWD and SPLT results on the foundation lane (adapted from Gomes Correia \& Magnan, 2012); (b) correlation between the SPLT results and the IC measurements on the foundation

The next phase consisted of the excavation of trenches for the preparation of the foundation's singularities. The materials used to fulfill this purpose were uncompacted soil and concrete for the low and high stiffness singularities, respectively.

The construction of the soil-rockfill mixture layer started with the spreading of the material, bearing in mind that the test section area included three different lanes which would be compacted by three different technologies (Conventional Compaction - CC; Intelligent Compaction - IC; and Continuous Compaction Control - CCC), as shown in Figure 3. Note that rollers equipped with IC technology have the option of turning the automatic adjustment of the vibratory parameters off, thus working as a regular roller equipped with continuous measurement of material stiffness (CCC) technology. The compaction process included FWD measurements every 2 roller passes, as well as topographical reference plate measurements on every pass, for each lane. The process was accomplished carrying out static plate load tests on the 9 previously selected points on the layer (6 on the soil-rockfill layers and 3 on the soil layer), as well FWD measurements throughout the length of the test section.

As far as the soil layer was concerned (Fig. 4), the same compaction methodology was used to achieve the final target values (degree of compaction), in this case obtained by nuclear moisture density gauge tests every 2 passes of the compactor.

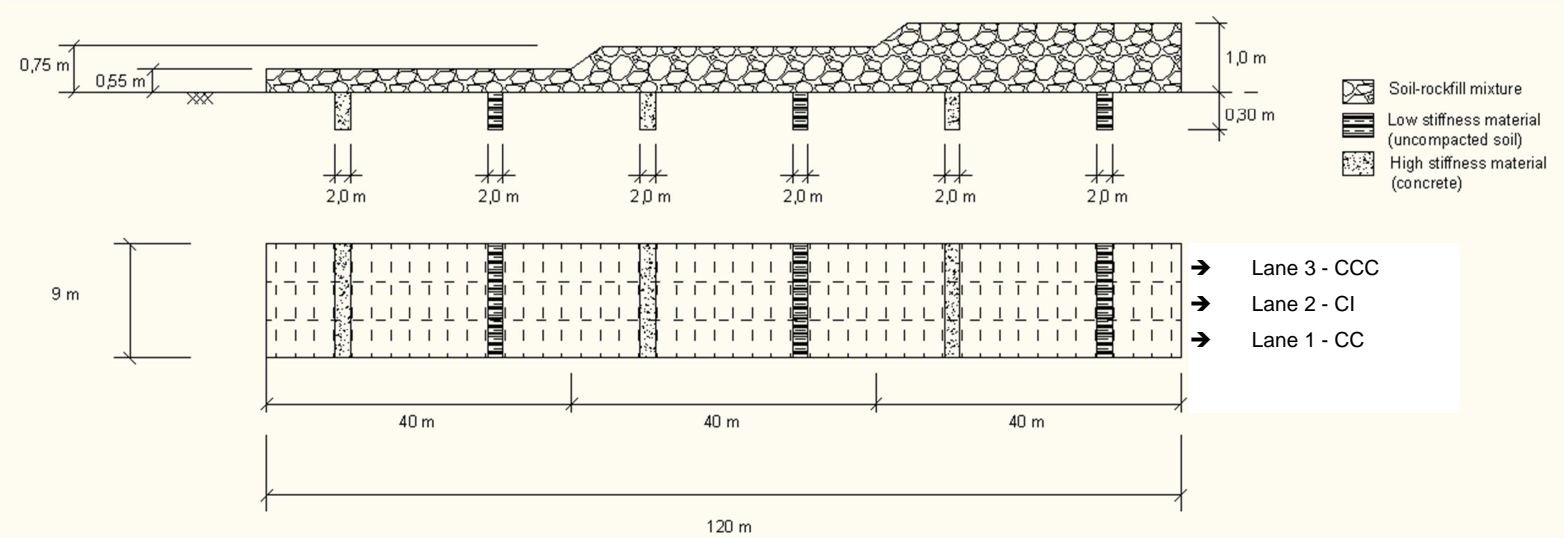

Fig. 3. Schema of the experimental section used in the demonstration project for soil-rockfill layers and technologies used in each lane 


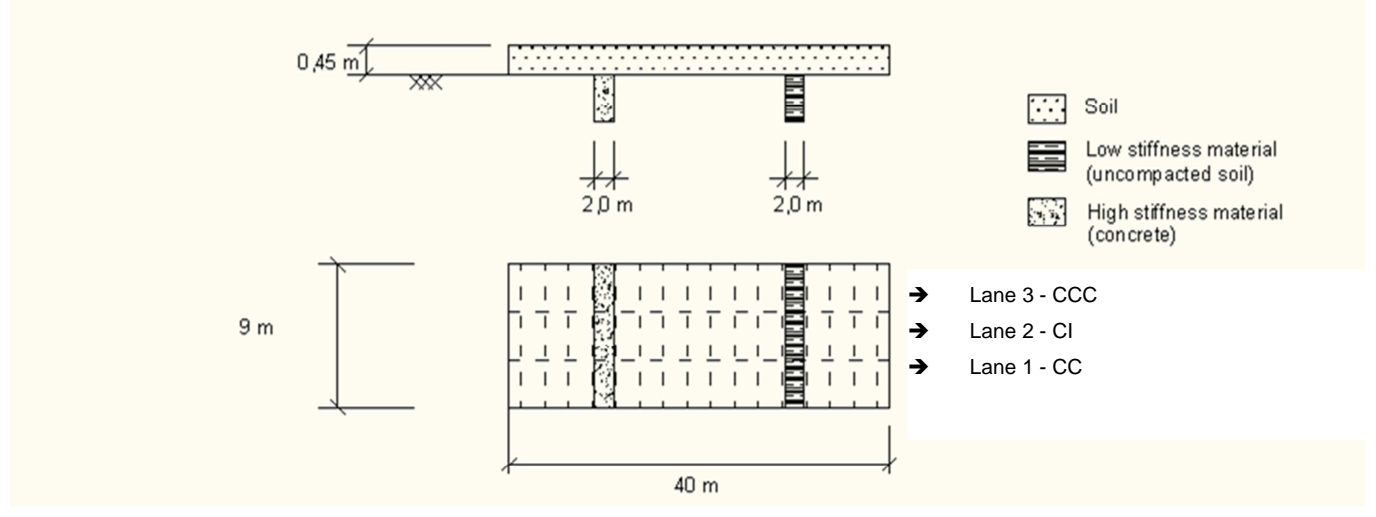

Fig. 4. Schema of the experimental section used in the demonstration project for soil layer and technologies used in each lane

\section{Results and discussion}

In this Chapter, the outcome obtained from the demonstration project measurements and tests are presented for both the soil-rockfill and soil layers, as well as a discussion of the results. Throughout the soil-rockfill layer section, the settlements obtained by topographical reference plate measurements are analysed, followed by the results and discussion associated with the FWD measurements. The correlation between the SPLT values and those originated from the IC technology measurements is also presented in this section. Regarding the soil section, the first analysis corresponds to the evolution of the degree of compaction measured with the nuclear density gauge (using the Modified Proctor as a reference) as a function of the number of roller passes, followed by the analysis of the deflection values obtained by the FWD measurements. In the end of each section, the verified in-situ effectiveness of the equipment capability to detect the foundation singularities (both lower and higher stiffness singularities) in each case is also discussed. Note that these measurement passes with the IC roller are performed using the technology in "manual" mode (CCC), so as to guarantee constant vibration parameters, thus resulting in an effective measurement at constant depths.

\subsection{Soil-rockfill layers}

In what concerns the soil-rockfill mixture layers, Figure 2a shows the variation of the obtained results, characteristic of highly heterogeneous materials such as soil-rockfill mixtures. Note that, even though the deformability values obtained from the IC measurement passes (Evib) and the SPLT $\left(\mathrm{E}_{\mathrm{v} 2}\right)$ cannot be directly compared, Figure $2 \mathrm{a}$ reflects the initial conditions of the foundation, as well as the good overall correlation of the obtained values. Only 2 out of 9 SPLT results are presented in the figure, since these measurements correspond to the ones carried out on lane 2 of the experimental section.

According to the GTR, the compaction of the soil-rockfill layers should be carried out in 4 (double) passes using high vibration amplitude, in order to guarantee compaction on the full depth of the material layers, and 2 final passes using low amplitude, in order to finalize compaction on the top layers. Furthermore, the GTR compaction tables do not include information regarding rollers equipped with IC technology, thus being limited to traditional compactors. In this context, even though the available IC technology roller was equivalent to a V4 according to the GTR (ignoring its IC features), the developer specifications indicated that it could achieve higher compaction energy than traditional V4 rollers, as a result of the association of the roller vibration characteristics with IC technology. As such, this comparison was also taken into account throughout the project.

The analysis of the evolution of layer settlement with the number of passages of both rollers (Fig. 5a) shows that, even though the IC technology V4 compactor shows an above average performance in the first few passes (especially comparing to a regular V4, as used in lane 3), the conventional V5 compactor obtains the highest settlement values when compared to the IC and CCC technologies for soil-rockfill mixes. This may be explained by the fact that the CC compactor has a superior operating class (V5) when compared to the IC compactor (V4). In other words, for this type of material, the associated W/L of the compactor, associated with the correspondent 
drum vibration characteristics, seems to be a decisive factor regarding the maximum compactive effort to which the material is subjected and therefore the maximum settlement values.
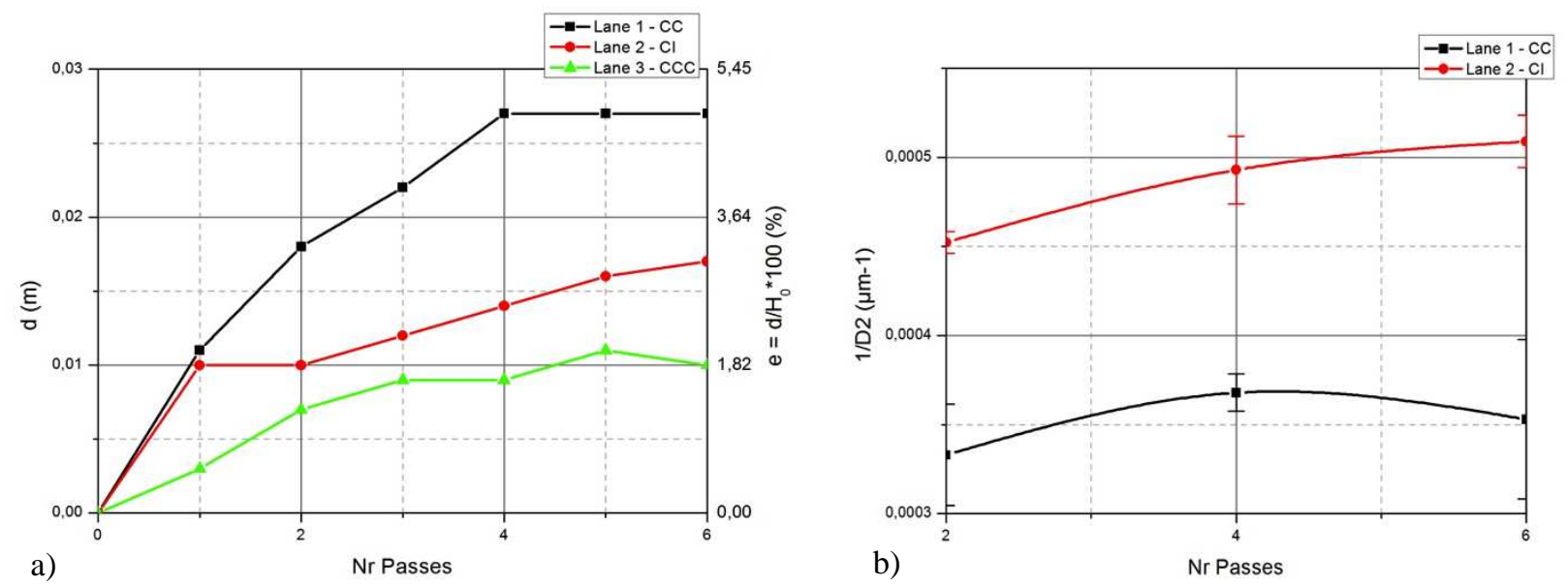

Fig. 5. (a) settlement measurements for the 0,55 m soil-rockfill layer; (b) FWD deflection measurements on the 0,55 $\mathrm{m}$ soilrockfill layer

Nonetheless, bearing in mind the example of the determined results from the FWD measurements, presented in Figure $5 \mathrm{~b}$ in terms of the inverse of deflection (1/D2) so as to be proportional to the deformability modulus, it is possible to evaluate the energy gain inherent to IC technology, as in the first passes there is a very significant increase in stiffness, which increases slowly from then on, as opposed to CC (lane 1), which apparently required 4 passes to achieve the material stiffness peak. Note that the CC technology, correspondent to lane 1, performed 4 passes on high amplitudes to maximize the effect of depth compaction and 2 passes on low amplitudes to finalize the surface compaction process. Furthermore, it is even noticeable in the $0,55 \mathrm{~m}$ thick layer that the material in lane 1, corresponding to the V5 roller (CC), presents an decrease in stiffness, possibly as a result of overcompaction of the material, while such effect doesn't occur with the IC technology for lane 2 . It is noteworthy that the lack of FWD measurements before the compaction process had been initiated ( 0 passes $)$ was due to the inexistence of operational conditions for the execution of the test, as a result of superficial irregularities and stability presented by the material before compaction.

Considering that the highest obtained stiffness values were achieved by the IC technology roller in lane 2 , these results may not seems consistent with the ones regarding the total settlement results previously discussed. One interpretation for this is related to the possibility that, for the $1,00 \mathrm{~m}$ and $0,75 \mathrm{~m}$ layers, the IC technology can only compact the layer to a certain limited depth (being unable to compact the whole depth of the layer), as opposed to the V5 CC roller, which is capable of transmitting enough compactive effort to compact greater depths. However, the fact that the roller in lane 2 is equipped with IC technology can lead to a more effective compaction within the more shallow depths evaluated by the FWD measurements, resulting in higher material stiffness values. Thus, while the CC roller may obtain better results in terms of layer settlements due to its ability to compact greater depths, the FWD measurement results indicate that the IC roller achieves the best results in terms of shallow material stiffness, even though the results obtained in first case (CC in lane 1) can lead to a better performance of the layer throughout its life cycle. Additionally, as the results presented in these measurements are the average value of several tests, excluding those done on the high and low stiffness singularity positions, the standard error for each point has also been included.

Using the $\mathrm{E}_{\mathrm{v} 2}$ values originated from the SPLT carried out on known points of the soil-rockfill layers, a correlation with the IC technology measurements was established (Fig. 6a), achieving a good adjustment between both measurements $\left(\mathrm{R}^{2}\right.$ of approximately 0,81$)$ on the current value range, especially considering the use of in-situ values. One extra SPLT test was carried out in order to evaluate the homogeneity of compaction throughout the layer. However, the wide range of values obtained by both measurement methods seem to 
indicate that the initial objective to achieve a highest as possible homogeneity regarding layer compaction was not achieved. In order to assess the cause behind this occurrence, the evolution of the relation between the average $\mathrm{E}_{\mathrm{vib}}$ values of layer modulus (Ec) and the foundation modulus (Ef) with the different soil-rockfill layer thicknesses was analysed (Fig. 6b). This comparison contributes with information on the obtained compaction level on each of the soil-rockfill layers ( 0,55 to $1,0 \mathrm{~m}$ thickness) using the foundation as a reference. Analysis of the results verify not only that the achieved degree of compaction not as effective on the higher thicknesses layer $(1,0 \mathrm{~m})$ as on the lower thickness layers $(0,55$ to $0,75 \mathrm{~m})$, but also that the IC roller obtained better compaction results within its measured/compacted depth (having achieved a minimum value of approximately 0,9 of the foundation stiffness, whereas the $\mathrm{CC}$ roller shows a minimum of approximately 0,8 of the foundation stiffness).

Additionally, it is relevant to refer that, should one have previously determined a target deformability value, it becomes possible to input this information to the IC roller, allowing it to convey only the necessary compaction effort to the material so as to achieve the target value. This option may allow the saving of immense amounts of time during construction, seeing how it can potentially reduce the required number of passes, while concurrently assuring the uniformity of the stiffness throughout the layer, eliminating the risk of both under and overcompaction, assuming that the roller has the necessary compaction energy potential.

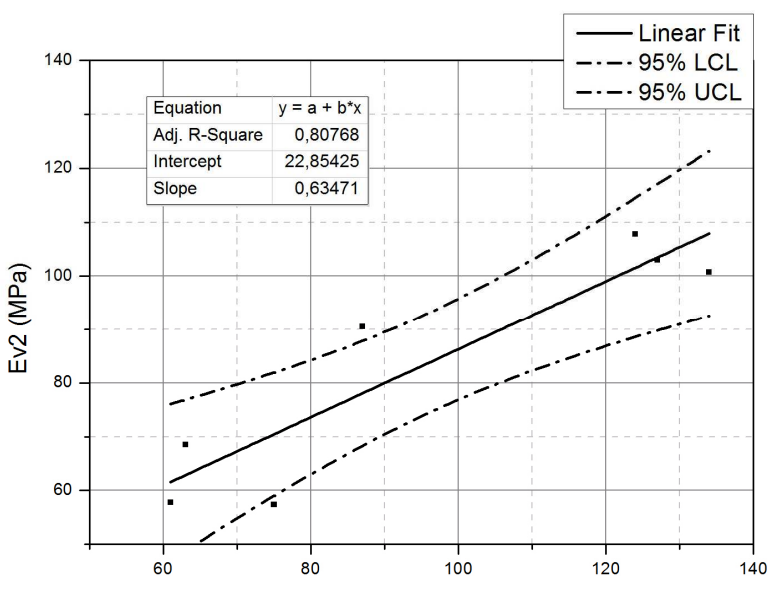

a)

Evib (MPa)

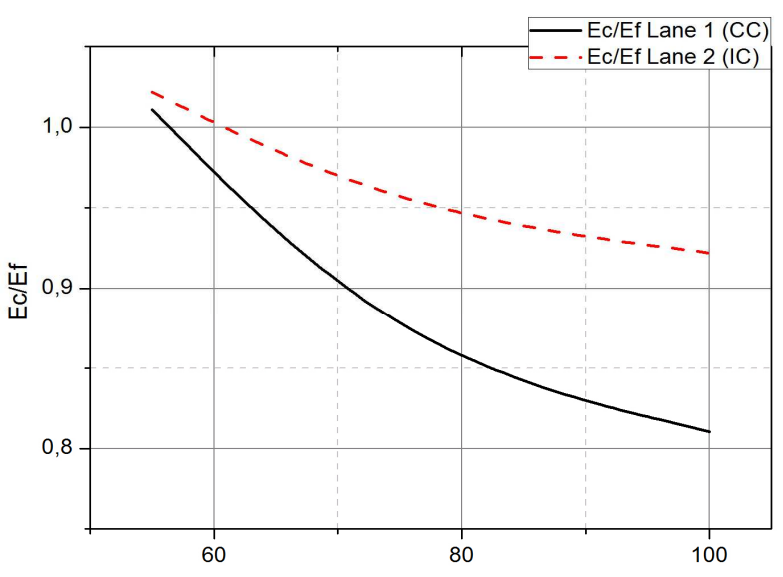

b)

Layer thickness $(\mathrm{cm})$

Fig. 6. (a) correlation between the SPLT results and the IC measurements on the soil-rockfill layers; (b) evolution of the layer modulus (Ec) / foundation modulus (Ef) ratio with the different soil-rockfill layer thicknesses

As far as the capability to detect the singularity areas on the foundation by the IC technology throughout the compaction process is concerned, the following outcome was observed (Fig. 7):

- The high heterogeneity inherent to soil-rockfill mixtures represents an inconvenience regarding the identification of each specific singularity build on the foundation, since punctual increases on the $\mathrm{E}_{\mathrm{vib}}$ value may indicate the presence of a higher stiffness element (rockfill) below the layer surface. Nevertheless, these areas seem to be identifiable on the 0,55 and 0,75 m layers;

- The IC roller did not seem to be able to give a clear indication of the presence of the singularities of uncompacted soil and concrete on the foundation of the $1,0 \mathrm{~m}$ thick layer, indicating that this thickness might be beyond the detection capabilities of the available V4 class IC roller; and

- Comparing the final compaction measurements with the measured foundation conditions (Fig. 2a), it is clear that the efficiency and homogeneity of compaction of the IC roller is higher on the 0,55 and $0,75 \mathrm{~m}$ thick layers, having also achieved the minimum target compaction values on all areas within these layers. However, the $1,0 \mathrm{~m}$ layer shows considerably inferior compaction values, as well as the inability to recover the lower stiffness measured in the same area (between the 80 and $120 \mathrm{~m}$ markers) on the foundation, thus indicating a drop of efficiency on this layer, which is consistent with previous conclusions. 


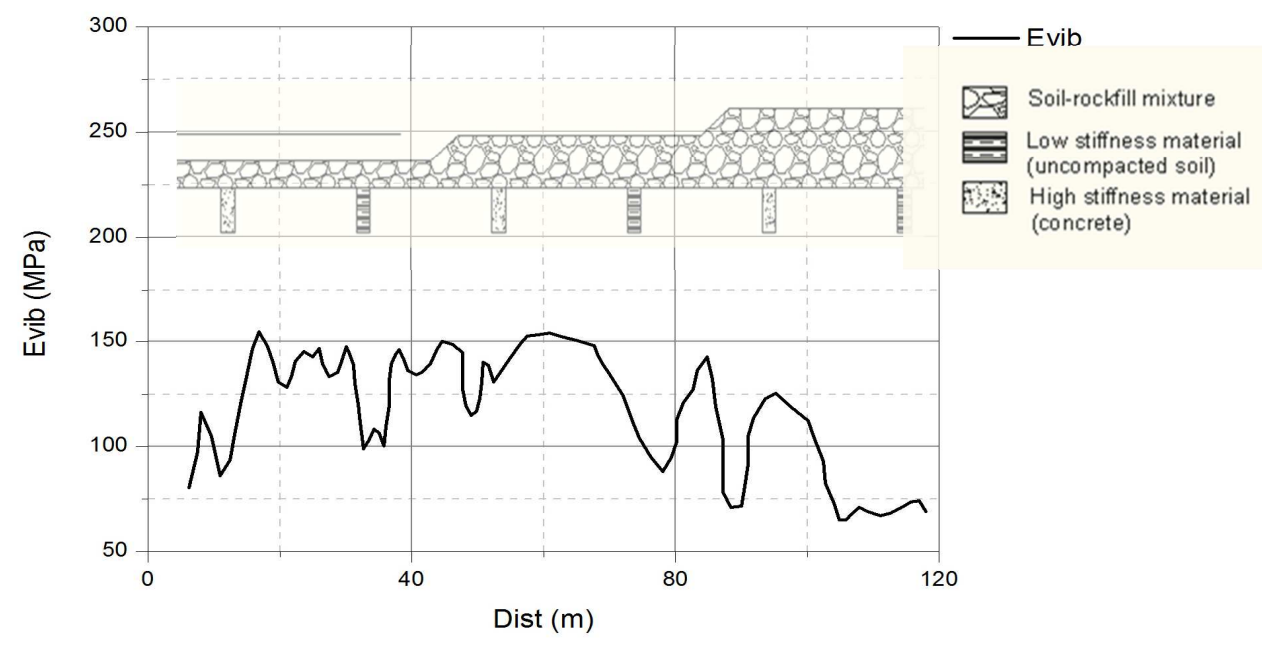

Fig. 7. IC measurements on soil-rockfill layers, with indication of the original position of the high and low stiffness singularities

\subsection{Soil layer}

Considering the soil layer, the IC roller equipped with automatic adjustment technology clearly achieves the best results regarding the final degree of compaction and compaction efficiency (Fig. 8a), when compared to CC and CCC technologies, which is reflected not only on the layer degree of compaction but also in the FWD results (Fig. 8b).

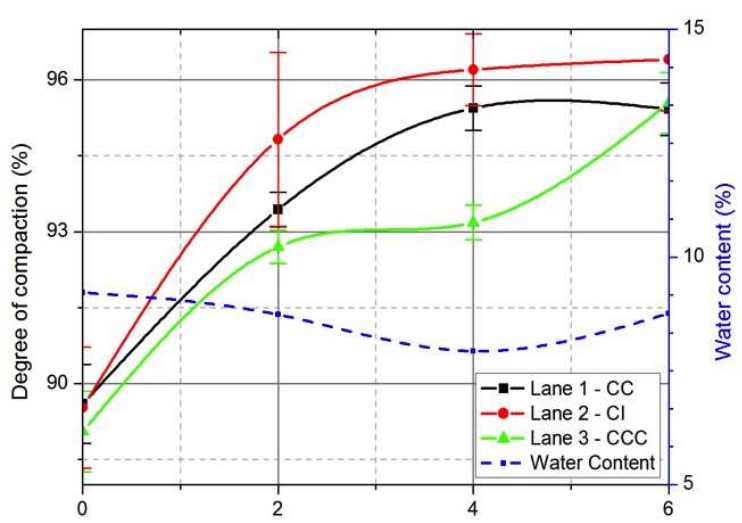

a)

Nr Passes

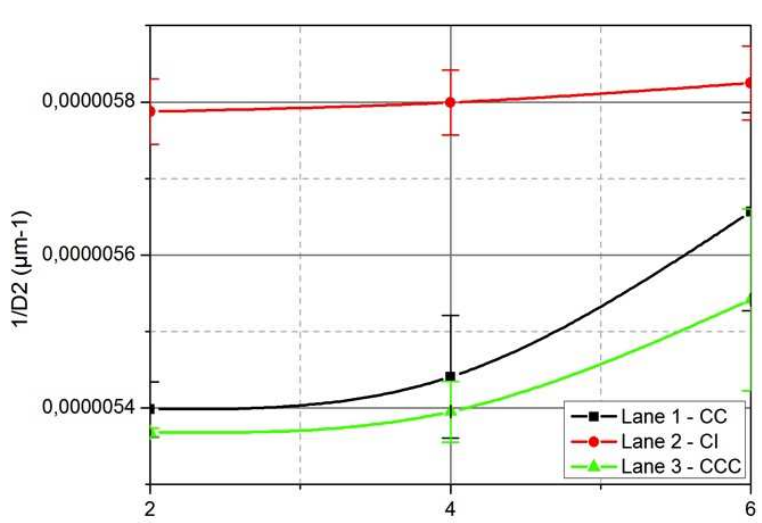

b)

Fig. 8. (a) degree of compaction on the soil layer, with indication of water contents; (b) FWD test results on the soil layer

It is to be emphasized that IC technology (in lane 2) in the soil material has a continuous effective compaction without overcompaction risks. In fact, the layer degree of compaction is either rising or constant throughout all the 6 passes, having significantly increased mainly in the first 2 passes, followed by a gradual increase in the remaining passes. During compaction, the IC equipment indicated that target compaction values had been achieved after 3 passes. Similarly to the process used on the previously discussed material, the compaction of the soil layer was carried out by 4 passes on high amplitudes (low frequencies) and 2 passes on low amplitudes, which may explain the significant increase on the degree of compaction detected on the last 2 passes in lane 3 , especially considering these results correspond to nuclear density gauge measurements $(0,30 \mathrm{~m}$ depth). Regarding the water content, evidence is provided that, on average, its value is approximately $1 \%$ below the optimum water content $(9.6 \%)$. 
When analysing the evolution of the inverse of the deflection (1/D2) with the number of passages (Fig. 8b), it is found that technologies CC and CCC appear to only reach a maximum value of material stiffness at the end of 6 passes. The stiffness increase measured by the FWD is significant in the 2 final passes of these technologies, which correspond to low amplitude (thus high frequency) compaction with the aim of completing the surface layers compaction process. Considering the previously discussed results regarding the nuclear density gauge measurements, IC technology was referred as having achieved better final results, reaching the maximum degree of compaction in the second passage and increasing gradually in the following passes, which is consistent with these FWD results.

Considering the high homogeneity of compaction obtained in the soil layer (Fig. 9), it was not possible to accomplish a correlation between the $\mathrm{E}_{\mathrm{vib}}$ values measured from the IC equipment and the $\mathrm{E}_{\mathrm{v} 2}$ values resulting from the 3 remaining SPLT tests. However, the $\mathrm{E}_{\mathrm{vib}} / \mathrm{E}_{\mathrm{v} 2}$ ratio was determined to be approximately 0,969 in the 45 to $55 \mathrm{MPa}$ range.

Finally, regarding the IC technology's capability of detecting the foundation singularities, one can infer that on the early passes both singularities are easily identifiable by the IC roller. However, by the end of the compaction process, only the singularity corresponding to the concrete material is visible in the roller output. This indicates that, in the case of the soil layer, the roller was able to compact the lower stiffness singularity which consisted of uncompacted soil present on the layer foundation. As a consequence, the final results show a good uniformity of the compaction achieved throughout the test section area, as depicted in Figure 9, in which the original position of the high and low stiffness singularities is also shown at 10 and $30 \mathrm{~m}$, respectively.

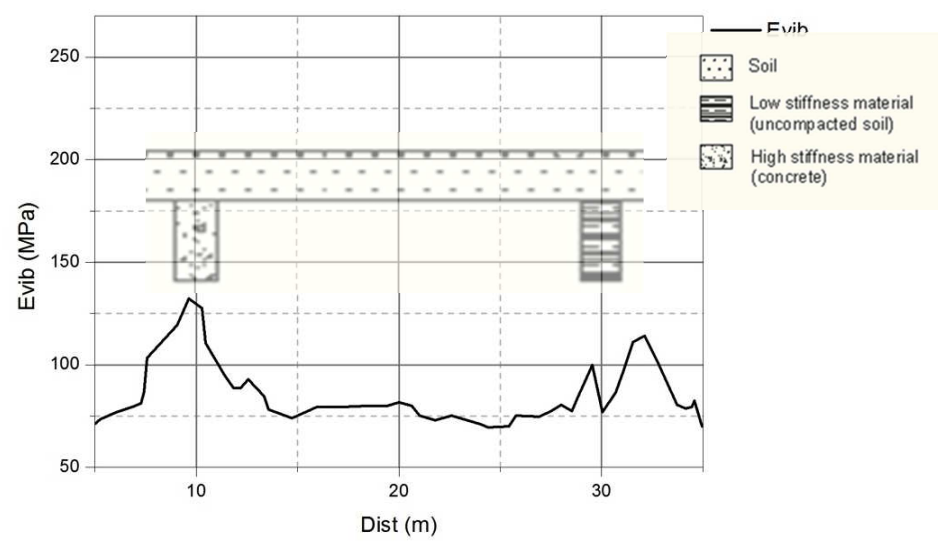

Fig. 9. IC measurements on the soll layer, with indication of the original position of the high and low stiffness singularities

\section{Conclusions}

The study concerning IC technology provides evidence that it offers technical and economic advantages in the optimization of the compaction process when compared to the conventional compaction method.

Recalling the demonstration project it may be concluded that the V4 roller BOMAG 213 may have lacked the necessary compaction energy to achieve the best results regarding the degree of compaction (assessed by settlement measurement) in the higher thickness layers adopted for the soil-rockfill mixture when compared to the performance of the higher W/L CC roller (V5). However, evidence indicates that, for the thickness layers compatible with both compactor classes V4 (IC) and V5, the performance of both rollers can be similar.

Nevertheless, it appears that in terms of getting maximum stiffness with minimum number of passes the IC technology can achieve equivalent or even higher results, particularly with regards to the compaction efficiency related to the low number of passes needed to achieve the highest possible stiffness. In fact, contrariwise to the results concerning the soil-rockfill mixture layers, the IC cylinder was found to achieve better results in the soil layer both regarding the maximum compaction obtained and compaction efficiency. Furthermore, it is evident that, as far as the soil layer is concerned, the IC roller had the ability to compact and resolve the problematic area 
consisting of low stiffness material (uncompacted soil) existent on the layer foundation, achieving a significant homogeneity in terms of degree of compaction and stiffness at the end of the compaction process.

In addition, during the demonstration project it was found that the IC roller is a very effective measuring instrument in the context of quality control, having not only the ability to assess the stiffness conditions of large areas in a very short time, but also the capability to identify and pinpoint potential problematic areas, especially regarding the results obtained in the soil layer.

\section{Acknowledgements}

The authors wish to thank FCT for the financial support (PEst-OE/ECI/UI4047/2011; SFRH/BD/71501/2010), as well Mota Engil, S.A. and particularly to Eng. Luís Gomes for providing all the field facilities.

\section{References}

Adam, D. (2007). Roller integrated continuous compaction control (CCC) technical contractual provisions \& recommendations. In A. Gomes Correia, Y. Momoya, \& F. Tatsuoka (Eds.), Design and Construction of Pavements and Rail Tracks: Geotechnical Aspects and Processed Materials (pp. 111-138). London, UK: Taylor \& Francis Group.

Adam, D., \& Brandl, H. (2003). Sophisticated roller integrated continuous compaction control. In Proceedings of the 12th Asian Regional Conference on Soil Mechanics and Geotechnical Engineering - Geotechnical Infrastructure for the New Millenium. Singapore.

Anderegg, R., \& Kaufmann, K. (2004). Intelligent compaction with vibratory rollers - feedback control systems in automatic compaction and compaction control. Journal of the Transportation Research Board, 124134.

Brandl, H. (2001). The importance of optimum compaction of soil and other granular materials. In A. Gomes Correia \& H. Brandl (Eds.), Geotechnics for Roads, Rail Tracks and Earth Structures (pp. 3-12). Balkema.

Camargo, F., Larsen, B., Chabourn, B., Roberson, R., \& Siekmeier, J. (2006). Intelligent Compaction: A Minnesota Case History. In Proceedings of the 54th Annual University of Minnesota Geotechnical Conference. Minneapolis, USA.

Forssblad, L. (1980). Compaction meter on vibrating rollers for improved compaction control. In Proceedings of the International Conference on Compaction (pp. 541-546). Paris, France.

Gomes Correia, A., \& Magnan, J. (2012). Trends and challenges in earthworks for transportation infrastructures. In Advances in Transportation Geotechnics 2 (pp. 1-12). Taylor \& Francis Group.

Gomes Correia, A., \& Quibel, A. (Eds.). (2000). Compaction of Soils and Granular Materials. Presse Nationale des Ponts et des Chaussées.

Hildebrandt, P. (2005). Compaction: Continuing developments may bring more sophistication in monitoring and testing your compaction results. Grading \& Excavation Contractor.

Petersen, L. (2005). Continuous compaction control MnROAD demonstration. Technical Report for the Minnesota Department of Transportation (Mn/DOT), Minneapolis, USA.

Rinehart, R. V., \& Mooney, M. a. (2008). Instrumentation of a roller compactor to monitor vibration behavior during earthwork compaction. Automation in Construction, 17(2), 144-150.

SETRA, \& LCPC. (1992). Guide des Terrassements Routiers - Réalisation des remblais e des couches de forme. Paris, France: Laboratoire Central des Ponts et Chaussees.

Thurner, H., \& Sandström, A. (1980). A new device for instant compaction control. In Proceedings of International Conference on Compaction (pp. 611-614). Paris, France.

White, D. J., Thompson, M. J., \& Vennapusa, P. K. R. (2007). Field Validation of Intelligent Compaction Monitoring Technology for Unbound Materials. Environmental Engineering. Technical Report for the Minnesota Department of Transportation (Mn/DOT), Minneapolis, USA. 